\title{
Full Day School Sebagai Penguatan Pendidikan Karakter (Perspektif Psikologi Pendidikan Islam)
}

\author{
Lis Yulianti Syafrida Siregar \\ Universitas Muhammadiyah Yogyakarta \\ Email : lisyulianti_siregar@yahoo.co.id
}

\begin{abstract}
Abstrak :
Penerapan full day school merupakan alternatif solusi dari revolusi pendidikan terhadap permasalahan yang terjadi di dunia pendidikan. Full day school adalah istilah dari proses pembelajaran yang dilaksanakan secara penuh, dimana aktifitas belajar anak dilakukan lebih banyak disekolah daripada dirumah. Proses belajar mengajar diberlakukan di pagi hari sampai dengan sore hari. Konsep dasar full day school sama dengan pendidikan Islam, dimana aplikasinya bertujuan agar memanfaatkan waktu dengan melakukan hal yang bermanfaat, ini adalah manifestasi dari belajar tanpa batas. Pendidikan Islam sebagai usaha untuk membimbing pertumbuhan dan perkembangan kepribadian siswa supaya mereka hidup sesuai dengan ajaran Islam. Pendidikan merupakan satu dari pembahasanpembahasan yang ada pada Al-Qur'an. Al-Qur'an merupakan firman Allah yang selanjutnya dijadikan pedoman hidup (way of life) kaum muslim yang tidak ada keraguan di dalamnya. Di dalamnya terkandung ajaran-ajaran pokok (prinsip dasar) menyangkut segala hal aspek kehidupan manusia, termasuk pendidikan. Al-Qur'an bisa dijadikan sebagai inspirasi untuk dikembangkan dalam rangka membangun pendidikan yang bermutu.
\end{abstract}

Kata kunci: Full day school, Pendidikan, Al-Qur'an

\begin{abstract}
:
Implementation of full day school is an alternative solution of the educational revolution to the problems that occur in education. Full day school is the term of the learning process that is carried out in full, where the learning activities of children done more school than at home. Teaching and learning process is applied in the morning until the afternoon. The basic concept of full day school is the same as Islamic education, where its application aims to make use of time by doing useful things, this is a manifestation of learning without limit. Islamic education as an effort to guide the growth and development of student personalities so that they live in accordance with the teachings of Islam. Education is one of the discussions that exist in the Qur'an.
\end{abstract}


The Qur'an is the word of Allah which is then used as a guide of life (way of life) of the Muslims that there is no doubt in it. It contains the basic teachings (basic principles) concerning all aspects of human life, including education. The Qur'an can serve as an inspiration to develop in order to build a quality education.

Keywords: Full day school, Education, Al-Qur'an

\section{Pendahuluan}

Pendidikan adalah segala pengaruh yang diupayakan sekolah terhadap peserta didik yang diserahkan oleh orangtua kepada pihak sekolah agar mempunyai kemampuan dan mengembangkan potensi yang dimiliki anak. Pendidikan merupakan usaha sadar yang dilakukan pemerintah melalui kegiatan bimbingan, pengajaran, atau latihan yang berlangsung di sekolah dan di luar sekolah sepanjang hayat, untuk mempersiapkan peserta didik agar dapat memainkan peranan dalam berbagai lingkungan hidup secara tepat dimasa yang akandatang. ${ }^{1}$

Beragam tanggapan muncul sehubungan dengan wacana program full day school yang digulirkan oleh menteri pendidikan dan kebudayaan Muhadjir Effendy sebagai program belajar tambahan untuk jenjang SD dan SMP yang sifatnya kokurikuler.

"Fullday sebenarnya pendidikan karakter. Itu pilihan kita menambah jam belajar di sekolah. Kemudian diisi dengan aktivitas-aktivitas macam-macam. Full day adalah cara mendongkrak sistem pendidikan kita yang masih rendah," Muhadjir Effendy di Hotel Grand Cempaka, Jalan Letjen R Soeprapto, Jakarta, Jumat $(19 / 8 / 2016){ }^{2}$

Bagi beberapa sekolah keagamaan, full day school diterapkan agar para guru dapat mengajarkan nilai-nilai spiritualitas dalam frekuensi yang lebih banyak. Misalnya, sekolah Islam yang mengadakan shalat dhuha, salat dzuhur, dan salat ashar berjamaah. Pada akhirnya, orang tua menginginkan anak-anaknya dibekali dengan pengetahuan agama yang mumpuni. Sedangkan kebanyakan orang tua merasa kurang capable untuk mengajarkan hal ini kepada anak-anak. ${ }^{3}$

\footnotetext{
${ }^{1}$ Suharsimi Arikunto, Manajemen Pengajaran Secara Manusiawi (Bandung: Rineka Cipta, Cet.II, 1993), 14

2 http://news.detik.com/berita/3278860/mendikbud-full-day-school-dongkrak-pendidikan-kita-yangmasih-rendah, di akses 28 september 2016

${ }^{3}$ Sukur Basuki, Harus Proporsional sesuai Jenis dan Jenjang Sekolah, http: // www.strkN1 Imj.sch.id/?diakses 4 oktober 2016
} 
Berdasarkan kajian psikologi eksperimental yang dilakukan para psikolog modern, bahwa pembagian waktu belajar atau latihan dalam jangka waktu tertentu yang diselingi masa istrahat, akan membantu dalam mempercepat proses belajar dan memantapkannya dalam ingatan ${ }^{4}$.

Tujuan pendidikan pada hakekatnya adalah meletakkan landasan karakter yang kuat melalui internalisasi nilai dalam pendidikan, menumbuhkan dan menanamkan kecerdasan emosi dan spiritual yang mewarnai aktivitas kehidupannya, menumbuhkan kemampuan berpikir kritis melalui pelaksanaan tugas-tugas pembelajaran, menumbuhkan kebiasaan dan berpartisipasi aktif secara teratur untuk memanfaatkan dan mengisi waktu luang dengan aktivitas belajar ${ }^{5}$.

Beberapa hal yang melatarbelakangi munculnya tuntutan full day school antara lain: Pertama, minimnya waktu orang tua dirumah berinteraksi dengan anak dikarenakan kesibukan dari tuntutan pekerjaan. Kedua, meningkatnya single parents danbanyaknya aktifitasorang tuayang kurangmemberikan perhatian pengawasan dan keamanan, serta kenyamanan terhadap segala tuntutan kebutuhan anak, terutama bagi anak usia dini. Ketiga, perlunya formulasi jam tambahan keagamaan bagi anak dikarenakan minimnya waktu orang tua bersama anak. Keempat, peningkatan kualitas pendidikan sebagai sebuah alternatif solusi terhadap berbagai permasalahan kemerosotan bangsa, terutama akhlak. Kelima, semakin canggihnya dunia komunikasi, membuat dunia seolah-olah tanpa batas (borderless world) yang dapat mempengaruhi perilaku anak jika tidak mendapat pengawasan dari orang dewasa. ${ }^{6}$

Dari kondisi tersebut di atas, para praktisi pendidikan merumuskan suatu paradigma baru dalam pendidikan yang disebut dengan full day school. Penerapan full day school dalam rangka memaksimalkan waktu luang anak-anak agar lebih berguna.

Sistem full day school dengan belajar sehari penuh bukanlah sistem baru dalam pendidikan Islam. Di Indonesia konsep pendidikan ini sudah ada sejak lama, yaitu di pondok pesantren. Umumnya siswa belajar sehari penuh bahkan sampai larut malam untuk mempelajari agama Islam (Al-Qur'an dan Hadist) dan pengetahuan umum

\footnotetext{
${ }^{4}$ Muhammad Usman Nadjati, Al Qur'an dan Psikologi, (Jakarta: Arus Pustaka, 2005),144

${ }^{5}$ Muhibbin Syah, Psikologi Pendidikan dengan Pendekatan Terpadu (Bandung: Rosdakarya, 2004), 154

${ }^{6}$ Agus Eko Sujianto, "Penerapan Full Day School Dalam Lembaga Pendidikan Islam: Jurnal Pendidikan, Ta'allim. Vol. 28.No.2, 204
} 
lainnya. Pendidikan ini terpola pada pendidikan pesantren yang menerapkan boarding school (sekolah berasrama).

Kaum muslim harus kembali kepada semangat pendidikan seumur hidup yang telah dicanangkan Rasulullah Saw. Banyak titah beliau yang menyemangati umat Islam akan pentingnya hidup bergelimang ilmu pengetahuan. Misalnya yang cukup dikenal adalah perintah menuntut ilmu bagi setiap muslim dan muslimah sejak saat dalam buaian sampai ke liang lahat.

Demikian pula al-Qur'an telah dengan jelas-jelas mengingatkan manusia supaya jangan meninggalkan generasi yang lemah baik dalam keimanan, materi, kesehatan, maupun pendidikan.

Sebagaimana dalam firman Allah Swt surat an-Nisaa'[4] ayat 9: “ Dan hendaklah takut kepada Allah orang-orang yang seandainya meninggalkan di belakang mereka anak-anak yang lemah, yang mereka khawatir terhadap (kesejahteraan) mereka. Oleh sebab itu hendaklah mereka bertakwa kepada Allah dan hendaklah mereka mengucapkan perkataan yang benar".

Perintah dalam al-Qur'an tersebut sudah seharusnya memicu masyarakat muslim untuk bersikap dengan dimensi yang lebih luas dalam beragama, terutama dalam menghadapi masalah pendidikan. Artinya, pendidikan harus dirajut sebagai bagian dari ibadah ${ }^{7}$.

Pendidikan menurut Islam atau pendidikan Islam yakni, pendidikan yang dipahami dan dikembangkan dari ajaran dan nilai fundamental yang terkandung dari sumber dasarnya yaitu Al-Qur'an dan as Sunnah ${ }^{8}$.

\section{Konsep Dasar Full Day School}

Istilah fullday school merupakan saduran dari B.Inggris dimana Full artinya penuh, day artinya hari dan school artinya sekolah. ${ }^{9}$. Jadi secara terminology fullday school artinya belajar sehari penuh. Jam belajar diberlakukan dari pagi sampai sore, mulai pukul 06.45 - 15.30 WIB, dengan durasi istrahat setiap dua jam sekali. Dengan demikian sekolah dapat mengatur jadwal pelajaran dengan leluasa, disesuaikan dengan bobot mata pelajaran dan ditambah dengan

\footnotetext{
7 A.Fathih Syuhud, "Pendidikan Islam di Era Globalisasi", http://www.sidogiri.com/modules.php?name=News\&file=article\&sid=333, diakses 26 september 2016

${ }^{8}$ Bashori Muchsin, Sulthan,\& Abdul Wahid. Pendidikan Islam Humanistik. (Bandung; PT.Refika Aditama, 2010), .6

${ }^{9}$ Jhon Echlos, KamusInggris Indonesia, (Jakarta:Gramedia, Cet. XXIII,1996), 259.
} 
pendalaman materi. Hal yang diutamakan dalam full day school adalah penagturan jadwal pelajaran dan pendalaman. ${ }^{10}$

Sistem full day school di Indonesia di awali dengan menjamurnya istilah sekolah unggulan sekitar tahun 1990-an, yang banyak dipelopori oleh sekolah-sekolah swasta termasuk sekolah-sekolah yang berlabel Islam. Dalam pengertian yang ideal sekolah unggul adalah sekolah yang berfokus pada kualitas proses pembelajaran, bukan pada kualitas input siswanya. Kualitas proses pembelajaran bergantung pada sistem pembelajarannya. Namun faktanya sekolah unggulan biasanya ditandai dengan biaya yang mahal, fasilitas yang lengkap dan serba mewah, elit, lain daripada yang lain, serta tenaga-tenaga pengajar yang profesional $^{11}$.

Tujuan pendidikan merupakan hasil akhir yang diharapkan oleh suatu tindakan mendidik. Mendidik merupakan tindakan sengaja untuk mencapai tujuan pendidikan. Sedangkan tujuan di dalam pendidikan merupakan suatu hal yang sangat urgen, sebab pendidikan tanpa sebuah tujuan bukanlah dikatakan sebagai pendidikan. ${ }^{12}$

Sebuah riset mengatakan bahwa siswa akan memperoleh banyak keuntungan secara akademik dan sosial dengan adanya full day. Lamanya waktu belajar juga merupakansalah satu dari dimensi pengalamananak. Full day school selain bertujuan mengembangkan mutu pendidikan yang paling utama adalah full day school bertujuan sebagai salah satu upaya pembentukan akidah dan akhlak siswa dan menanamkan nilai-nilai positif. ${ }^{13}$

Full day school merupakan suatu sistem pembelajaran yang dilaksanakan secara penuh, dimana aktifitas anak banyak dilakukan di sekolah daripada di rumah. Konsep dasar dari full day school adalah integrated curiculum dan integrated activity yang merupakan bentuk pembelajaran yang diharapkan dapat membentuk seorang anak (siswa) yang berintelektual tinggi yang dapat memadukan aspek ketrampilan dan pengetahuan dengan sikap yang baik. ${ }^{14}$

Dasar pendidikan dari penerapan full day schoolsama dengan dasar pendidikan Islam. Pendidikan Islam adalah usaha untuk membimbing ke arah pertumbuhan

\footnotetext{
${ }^{10}$ Baharuddin, Pendidikan dan Psikologi Perkembangan, (Jogjakarta: Ar Ruzz Media, 2009), 9

${ }^{11}$ Agus Eko Sujianto, "Penerapan Full Day School Dalam Lembaga ....,. 204

${ }^{12}$ Ahmad Tafsir, Ilmu Pendidikan dalam Perspektif Islam, (Bandung: Remaja Rosdakarya,1992),32.

${ }^{13}$ Schudin, Pengaruh Pelaksanaan Pembelajaran Full Day School Terhadap Akhlak Siswa (Surabaya: Perpustakaan IAIN Sunan Gunung Djati, 2005), 16

${ }^{14}$ Suharsimi Arikunto, Manajemen Pengajaran Secara Manusiawi...,4
} 
kepribadian peserta didik secara sistematis dan pragmatis supaya mereka hidup sesuai dengan ajaran Islam, sehingga tercapai kebahagiaan dunia dan akhirat ${ }^{15}$.

Melihat fenomena empirik yang terjadi di masyarakat, terutama terkait dengan pengaruh negatif yang disebabkan lingkungan, maka dirasa perlu untuk melakukan pengontrolan waktu luang anak. Secara utuh dapat dilihat bahwa pelaksanaan sistem full day school mengarah pada beberapa tujuan, antara lain:

a. Orang tua tidak akan merasa khawatir anaknya terkena pengaruh negatif lingkungan, karena anaknya akan seharian penuh berada di sekolah yang artinya sebagian waktunya dimanfaatkan untuk belajar

b. Untuk memberikan pengayaan dan pendalaman materi sekolah

c. Memberikan pembiasaan-pembiasaan hidup yang baik

d. Melakukan pembinaan mental dan spiritual anak

Konsep pengembangan dan inovasi sistem pembelajaran full day school adalah untuk mengembangkan kreatifitas yang mencakup integrasi dari kondisi tiga ranah yaitu kognitif, afektif, dan psikomotor. Sistem pembelajaran full day school merupakan pengemasan dalam hal metode belajar yang berorientasi pada kualitas pendidikan berlangsung selama sehari penuh dengan menggunakan integrated activity yang menyenangkan dalam pembelajaran ${ }^{16}$

Model atau metode pembelajaran yang bervariasi akan menambah kesan dan warna suasana pembelajaran yang berbeda-beda. Semakin bervariasi suatu metode pembelajaran,akan semakin dinamis proses pembelajaran tersebut ${ }^{17}$

Pengajaran yang dilakukan dengan kegembiraan akan memperlambat kelelahan, baik dari pihak guru maupun dari pihak siswa. Pada segi lain pengajaran yang diisi dengan kegembiaraan dapat membantu pemusatan perhatian ${ }^{18}$

Sistem full day school mempunyai sisi keunggulan, antara lain:

1. Sistem full day school lebih memungkinkan terwujudnya pendidikan secara utuh. Benyamin S Bloom menyatakan bahwa sasaran obeyektifitas pendidikan meliputi tiga ranah, yaitu kognitif, afektif, dan psikomotor. Karena memalui sistem full day

\footnotetext{
${ }^{15}$ Achmad Patoni, Metodologi Pendidikan Agama Islam, (Jakarta: Bina Ilmu, 2004), 15

${ }^{16}$ Romli, Moch, ,Manajemen Pembelajaran di Sekolah Dasar Full Day School, (Disertasi UM Malang,2004), 18

${ }^{17}$ Mujamil Qomar, Kesadaran Pendidikan: Sebuah Penentu Keberhasilan Pendidikan. (Jogjakarta: Ar Ruzz, 2012), 75

${ }^{18}$ Binti Maunah, Metodologi Pengajaran Agama Islam, (Yogyakarta: Teras,2009), .30
} 
school tendensi ke arah penguatan pada sisi kognitif saja dapat lebih dihindarkan, dalam arti aspek afektif siswa dapat lebih diarahkan demikian juga dengan aspek psikomotorik.

2. Sistem full day school lebih memungkinkan terwujudnya intensifikasi dan efektivitas proses edukasi. Full day school dengan menggunakan waktu lebih panjang sangat memungkinkan bagi terwujudnya intensifikasi proses pendidikan dalam arti siswa lebih mudah diarahkan dan dibentuk sesuai dengan misi dan aorientasi pendidikan, sebab aktivitas siswa lebih mudah terpantau

3. Sistem full day school merupakan sistem pendidikan yang terbukti efektif dalam mengaplikasikan kemampuan siswa dalam segala hal, seperti aplikasi Pendidikan Agama Islam (PAI) yang mencakup semua aspek baik itu ranah kognitif, afektif, dan psikomotor $^{19}$.

Namun demikian, sistem pembelajaran full day school ini tidak terlepas dari kelemahan atau kekurangan, antara lain:

1. Sistem full day school acapkali menimbulkan rasa bosan pada siswa. Sistem pembelajaran full day school membutuhkan kesiapan fisik, psikologis dan intelektual yang bagus. Diperlukan kejelian dan improvisasi pengelolaan sehingga tidak monoton dan membosankan

2. Sistem full day school memerlukan perhatian dan kesungguhan manajemen bagi lembaga pengelola, agar proses pembelajaran berlangsung optimal. Dibutuhkan sarana dan prasarana pendukung yang bersifat fisik (material).

3. Tenaga pengajar(pendidik) profesional, dan kompeten di bidangnya. ${ }^{20}$

Jadi pelaksanaan full day school adalah memberikan dasar yang kuat terhadap siswa dan untuk mengembangkan minat dan bakat serta meningkatkan kecerdasan siswa dalam segala aspek. Hanya saja dalam aplikasinya perlu didukung oleh berbagai aspek seperti halnya sarana dan prasaran pendidikan, pendidik (guru sekolah) dan kurikulum. Dengan demikian sekolah yang disyaratkan memenuhi kriteria full day school dapat secara efektif, yang mampu mengelola dan memanfaatkan segala sumber daya yang dimiliki.

\footnotetext{
${ }^{19}$ Nor Hasan, "Full Day School Model Alternatif Pembelajaran PAI", Jurnal Pendidikan Tadris, Vol.1 No.1, 2006, 114-115

${ }^{20}$ Sekolah Kehidupan Berbasis Realitas (Kritik Atas Gagasan Program “Full Day School”) http://researchingines.com/lidusyardi.html.diakses 3 Oktober 2016
} 


\section{Pendidikan Full day school berbasis Al-Qur'an}

Dasar pendidikan Islam sudah jelas bersumber dari firman Allah SWT dan Sunnah Rasulullah SAW yaitu Al Qur'an dan Hadist. Melaksanakan pendidikan adalah merupakan perintah agama dan Allah SAW dan merupakan bentuk ibadah kepadaNya. ${ }^{21}$ Dalam AlQur'an banyak ayat-ayat yang menunjukkan perintah tersebut, antara lain:

Dalam surat Al-Isra' ayat72 yang berbunyi :

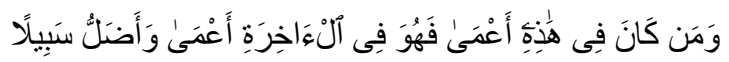

"Dan barangsiapa yang buta (hatinya) di dunia ini, niscaya di akhirat (nanti) ia akan lebih buta (pula) dan lebih tersesat dari jalan (yang benar).“

(QS. Al-Isra: 72) ${ }^{22}$

Dalam surat Ar-Rahman ayat 1-4 yang berbunyi:

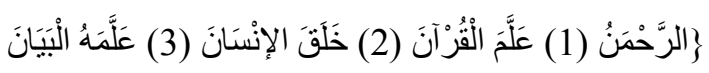

“Tuhan yang maha pemurah, yang mengajarkan Al-Qur'an dan menciptakan manusia mengajarnya pandai berbicara" (QS. Ar-Rahman: 1-4)

Dalam Al Qur'an surat Ali Imron ayat 104 yang berbunyi: ${ }^{23}$

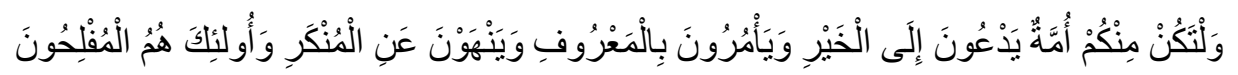

“ Dan hendaklah ada diantara kamu segolongan umat yang menyeru kepada kebajikan, menyuruh kepada yang ma'ruf dan mencegah dari yang munkar, merekalah orang-orang yang beruntung" (QS. Ali Imran: 104)

Dalam surat At-Tahrim ayat 6 yang berbunyi:

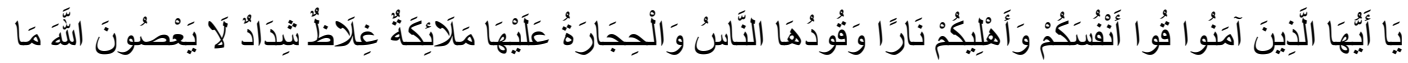

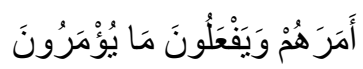

"Hai orang-orang yang beriman, peliharalah dirimu dan keluargamu dari api neraka yang bahan bakarnya adalah manusia dan batu, penjaganya malaikatmalaikat yang kasar, keras,dan tidak mendurhakai Allah terhadap apa yang diperintahkanNya kepada mereka dan selalu menagajarkan apa yang diperintahkan” (QS. At-Tahrim: 6)

Dalam surat An-Nahl ayat 125 yang berbunyi:

\footnotetext{
${ }^{21}$ Achmadi, Ideologi Pendidikan Islam Paradigma Humanisme Teosentris, (Yogyakarta: Pustaka Pelajar,2005), 29

${ }^{22}$ Al- Qur'an digital

${ }^{23}$ Ibid
} 

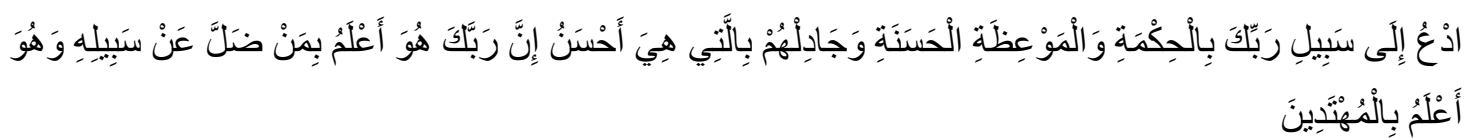

"Serulah (manusia) dengan jalan Tuhanmu dengan hikmah dan pelajaran yang baik dan bantahlah mereka dengan cara yang baik. Sesungguhnya Tuhanmu dialah yang lebih mengetahui tentang siapa yang tersesat dari jalanNya dan dialah yang lebih mengetahui orang-orang yang mendapat petunjuk” (QS. An-Nahl: 125)

Ayat-ayat Al Qur'an di atas merupakan seruan dari Allah kepada manusia baik laki-laki maupun perempuan agar tidak menyia-nyiakan waktu dengan melakukan halhal yang tidak bermanfaat. Full day school merupakan manifestasi belajar tanpa batas. Mengacu pada ayat-ayat tersebut di atas bahwa sistem full day school siswa dihadapkan pada aktifitas-aktifitas belajar yang menguntungkan selama sehari penuh, sehingga siswa tidak ada waktu luang untuk melakukan aktifitas-aktifitas yang sifatnya negatif dan kurang menguntungkan.

Penerapan sistem full day schoool yang berbasis Al-Qur'an sudah diterapkan pada pendidikan berbasis agama, khususnya pada lembaga pendidikan seperti sekolah Islam Terpadu. Sekolah IslamTerpadu pada hakekatnya adalah sekolah yang mengimplementasikan konsep pendidikan Al-Qur'an berdasarkan Al-Qur'an dan As-Sunnah. ${ }^{24}$

Dalam aplikasinya sekolah Islam Terpadu diartikan sebagai sekolah yang menerapkan pendekatan penyelenggaraan dengan memadukan pendidikan umum dan pendidikan agama menjadi suatu jalinan kurikulum. Kurikulum yang digunakan bersifat integrative yaitu paduan dari kurikulum nasional (diknas) dan kurikulum pesantren (materi pelajaran keIslaman). Konsep integratif dapat berarti bahwa dalam proses pembelajaran memadukan secara utuhranah kognitif, afektif,danpsikomotor. Dalam penyelenggaraannya sekolah Islam terpadu mengusung konsep “one for all”. Artinya, dalam satu atap sekolah peserta didik akan mendapatkan pendidikan umum, pendidikan agama, dan pendidikan ketrampilan ${ }^{25}$

\section{Implementasi Full Day School dalam tinjauan Psikologi Pendidikan Islam}

\footnotetext{
${ }^{24}$ Marfiah Astuti, "Implementasi Full Day School Sebagai Usaha Mendorong Perkembangan Sosial Peserta Didik TK Unggulan Al-Ya'lu Kota Malang”,Jurnal Kebijakan dan Pengembangan Pendidikan,Vo.1 No.2, Juli 2013

${ }^{25}$ Primarnie, Armie, Sekolah IslamTerpadu (Konsep dan Aplikasinya), (Jakarta: JSIT Indonesia, 2015), 54
} 
Full day school merupakan model sekolah umum yang memadukan sistem pengajaran Islam secara intensif yaitu dengan memberi tambahan waktu khusus untuk pendalaman agama siswa. Hal ini sejalan dengan tuntutan ajaran agama Islam. Banyaknya ayat Al-Qur'an maupun hadist yang menganjurkan mencari ilmu. Bahkan ayat yang pertama turun kepada Nabi Muhammad Saw adalah surat Al'Alaq yang artinya:

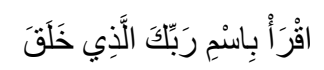

“Bacalah dengan (menyebut) nama Tuhanmu Yang menciptakan” (QS.Al'Alaq: 1)

Disamping itu di dalam hadist nabi Muhammad Saw memerintahkan kepada kita untuk belajar tanpa batas dimanapun dan kapanpun. Berikut hadist tentang menuntut ilmu.

$$
\text { من خرج فى طلب العلم فهو فى سبيل الله حتى يرجع }
$$

Artinya : "Barang siapa yang keluar untuk mencari ilmu maka ia berada di jalan Allah hingga ia pulang". (HR. Turmudzi).

$$
\text { طلب العلم منالمهذ الى الهد }
$$

Artinya: "tuntulah ilmu sejak dari ayunan sampai ke liang lahat”(H.R Muslim).

$$
\text { طلب العلم فريضة على كل مسلم و مسلمة }
$$

Artinya: "Menuntut ilmu itu diwajibkan bagi setiap orang Islam" (Riwayat Ibnu Majah, Al-Baihaqi, Ibnu Abdil Barr, dan Ibnu Adi, dari Anas bin Malik).

$$
\text { من سلك طريق يلتمس فيه علم سهل الله له طريق الى الجنه (رواه مسلم) }
$$

Artinya: "Barang siapa yang menempuh suatu jalan untuk menuntut ilmu, Allah akan memudahkan baginya jalan ke surga" (HR Muslim)

Ayat dan hadist di atas merupakan seruan dari Allah kepada manusia baik lakilaki maupun perempuan agar tidak menyia-nyiakan waktu dengan melakukan hal-hal yang tidak bermanfaat. Full day school merupakan manifestasi dari belajar tanpa batas. Mengacu pada ayat di atas bahwa dalam dalam sistem full day school siswa dihadapkan pada aktifitas-aktifitas belajar yang menguntungkan selama sehari penuh,sehingga siswa tidak ada waktu luang untuk melakukan aktifitas-aktifitas yang sifatnya negatif dan kurang menguntungkan.

Penerapan sistem full day school mempunyai tujuan utama yaitu membentuk kualitas akhlak siswa. Dan agar tujuan dari sistem full day school tercapai dilakukan bimbingankhusus keagamaan yaitu antara lain dengan bimbingan shalat di sekolah 
Sistem full day school banyak diterapkan di sekolah yang berbasis agama, yang memiliki keunggulan tersendiri, diantaranya adalah:Pertama,Anak mendapat pengetahuan umum antisipasi terhadap terhadap perkembangan ilmu pengetahuan. Kedua,Anak memperoleh pendidikan keIslaman secara layak dan proporsional. Ketiga,Anak mendapatkan pendidikan kepribadian yang bersifat antisipatif terhadap perkembangan sosial budaya yang ditandai dengan derasnya arus informasi dan globalisasi yang membutuhkan nilai saring. Empat,Potensi anak tersalurkan melalui kegiatan-kegiatan ekstrakurikuler. Lima,Perkembangan minat, bakat, dan kecerdasan anak terpantau dari sejak dini melalui program bimbingan dan konseling

Garis-garis besar program full day school adalah sebagai berikut:

1. Membentuk sikap yang Islami

a. Pembentukan sikap yang Islami

(1) Pengetahuan dasar tentang Iman, Islam, dan Ihsan

(2) Pengetahuan dasar tentang akhlak terpuji dan tercela

(3) Kecintaan kepada Allah dan RasulNya

(4) Kebanggaan kepada Islam dan semangan memperjuangkannya

b. Pembiasaan berbudaya Islam

(1) Gemar beribadah

(2) Gemar belajar

(3) Disiplin

(4) Kreatif

(5) Mandiri

(6) Hidup bersih dan sehat

(7) Adab-adab Islam

2. Penguasaaan pengetahuan dan ketrampilan

a. Pengetahuan materi-materi pokok program pendidikan

b. Mengetahui dan terampil dalam beribadah sehari-hari

c. Memahami secara sederhana isi kandungan amaliyah sehari-hari

Dalam rangka memaksimalkan waktu luang anak-anak agar lebih berguna, maka diterapkanlah sistem full day school dengan tujuan pembentukan akhlak dan akidah dalam menanamkan nilai-nilai yang positif, serta memberikan dasar yang kuat dalam belajar di segala aspek. Agar semua dapat terakomodir, kurikulum dalam sistem 
pembelajaran full day school didesain untuk menjangkau masing-masing begian dari perkembangan siswa ${ }^{26}$

\section{Penutup}

Mempersiapkan anak hidup pada masanya adalah kewajiban semua pihak, termasuk di dalamnya orang tua, sekolah, guru, masyarakat dan pemerintah. Faktor yang sangat menentukan mempersiapkan generasi mendatang adalah lingkungan dan pendidikan dimana anak tumbuh dan berkembang. Oleh karenanya harus dipersiapkan pola pendidikan yang dapat mengembangkan fitrah manusia serta lingkungan yang mendukung upaya pencapaian tersebut.

Karakterisitik yang mendasar dalam sistem pendidikan full day school adalah proses integrated activity dan integrated curiculum dalam pelaksanaannya,dengan metode pengajaran yang menarik minat, kreatif, dan inovatif disertai pengayaan.Siswa dihadapkan pada aktifitas-aktifitas belajar yang menguntungkanselama sehari penuh, sehingga siswa tidak ada waktu luang untuk melakukan aktifitas-aktifitas yang sifatnya negatif dan tidak menguntungkan.

Full day school selain bertujuan mengembangkan mutu pendidikan yang paling utama adalah full day school bertujuan sebagai salah satu upaya pembentukan akidah dan akhlak siswa dan menanamkan nilai-nilai positif. Full day school merupakan manifestasi belajar tanpa batas. Hal ini sangat relevan dengan Pendidikan Islam yang berlandaskan Al Qur'an dan Hadist.

\footnotetext{
${ }^{26}$ Schudin, Pengaruh Pelaksanaan Pembelajaran Full Day School.., 18
} 


\section{Daftar Pustaka}

Patoni, Achmad. 2004, Metodologi Pendidikan Agama Islam, Jakarta: Bina Ilmu.

Achmadi, 2005, Ideologi Pendidikan Islam Paradigma Humanisme Teosentris, Yogyakarta: Pustaka Pelajar.

Agus Eko Sujianto, Penerapan Full Day School Dalam Lembaga Pendidikan Islam, Jurnal Pendidikan, Ta'allim. Vol 28.No.2, Nopember 2015 Tulungagung

Tafsir, Ahmad. 1992, Ilmu Pendidikan dalam Perspektif Islam,Bandung: Remaja Rosdakarya.

Al- Qur'an digital

Baharuddin, 2009. Pendidikan dan Psikologi Perkembangan, Jogjakarta: Ar Ruzz Media.

Muchsin, Bashori Sulthan, Moh.,\& Wahid, Abdul. 2010, Pendidikan Islam Humanistik. Bandung; PT.Refika Aditama.

Maunah, Binti. 2009, Metodologi Pengajaran Agama Islam, Yogyakarta: Teras.

Echlos, Jhon. 1996, KamusInggris Indonesia, Jakarta:Gramedia, Cet. XXIII.

Astuti, Marfiah. Implementasi Full Day School Sebagai Usaha Mendorong Perkembangan Sosial Peserta Didik TK Unggulan Al-Ya'lu Kota Malang. (Jurnal Kebijakan dan Pengembangan Pendidikan,Vo.1 No.2, Juli 2013

Muhaimin, 2004, Paradigma Pendidikan Islam, Bandung: PT.Remaja Rosdakarya.

Usman, Muhammad Nadjati, 2005, Al Qur'an dan Psikologi, Jakarta: Arus Pustaka.

Syah, Muhibbin. 2004, Psikologi Pendidikan dengan Pendekatan Terpadu, Bandung: Rosdakarya,.

Qomar, Mujamil. 2012, Kesadaran Pendidikan: Sebuah Penentu Keberhasilan Pendidikan. Jogjakarta: Ar Ruzz.

Hasan, Nor. Full Day School (Model Alternatif Pembelajaran PAI), Jurnal Pendidikan Tadris. Vol.1 No.1, 2006

Armie, Primarnie. Sekolah IslamTerpadu (Konsep dan Aplikasinya), Jakarta: JSIT Indonesia 
Romli, Moch, , 2004, Manajemen Pembelajaran di Sekolah Dasar Full Day School, Disertasi UM Malang.

Schudin, 2005, Pengaruh Pelaksanaan Pembelajaran Full Day School Terhadap Akhlak Siswa, Surabaya: Perpustakaan IAIN Sunan Gunung Djati.

Arikunto, Suharsimi. 1993, .Manajemen Pengajaran Secara Manusiawi, Bandung: PT.Rineka Cipta. 